\title{
FAKTOR - FAKTOR YANG BERHUBUNGAN DENGAN REALISASI ANGGARAN BANTUAN OPERASIONAL KESEHATAN(BOK) DI PUSKESMAS KOTA KENDARI
}

\author{
Naomi Somaliggi ${ }^{1}$, Kamalia ${ }^{2}$ Sanihu Munir ${ }^{3}$ \\ ${ }^{1,2,3}$ Program Studi Kesehatan Masyarakat STIKES Mandala Waluya Kendari \\ Email: naomisomalinggi@gmail.com
}

\begin{abstract}
ABSTRAK
Bantuan Operasional Kesehatan merupakan salah satu program pemerintah melalui Kementerian Kesehatan. Sumber dana Bantuan Operasional Kesehatan yaitu APBN melalui Dana Tugas Pembantuan Kementrian Kesehatan. Bantuan Operasional Kesehatan merupakan upaya pemerintah pusat dalam membantu pemerintah daerah untuk mencapai target nasional di bidang kesehatan yang menjadi tanggung jawab daerah. Tujuan penelitian ini adalah untuk menganalisis faktor-faktor yang berhubungan dengan realisasi anggaran BOK dan cakupan program kesehatan.Metode penelitian yang digunakanadalah penelitian kuantitatif dengan rancangan Cross Sectional Study yaitu penelitian yang dilakukan pada waktu dan tempat secara bersamaan.Hasil penelitian menunjukkan bahwa pelaksanaan program dana Bantuan Operasional Kesehatan pada tahap proses : yang menyangkut Perencanaan, Pengorganisasian Pelaksanaan, Pelaporan Pemantauan atau monitoring pada umumnya sudah berjalan sesuai juknis kecuali perencanaan masih perlu penekanan kepada Kepala Puskesmas.Sehingga dapat di simpulkan Ada hubungan sedang antara perencanaan dengan realisasi bantuan operasional kesehatan di Puskesmas
\end{abstract}

Kata Kunci: BOK, Anggaran Operasional Kesehatan, PUSKESMAS

\begin{abstract}
Health Operational Budget is one of the government programs through the Ministry of Health. The source of funding for Health Operational Assistance is the State Budget through the Ministry of Health Assistance Task Fund. Health Operational Assistance is an effort of the central government in helping local governments to achieve national targets in the health sector which are the responsibility of the region. The purpose of this study was to analyze the factors related to the realization of the BOK budget and health program coverage. The research method used is quantitative research with a crosssectional study design that is research conducted at the same time and place. The results showed that the implementation of the Health Operational Assistance fund program at the stage of the process: which involved Planning, Organizing Implementation, Reporting Monitoring or monitoring, in general, had been proceeding according to technical guidelines except that planning still needed to be emphasized to the Head of the Puskesmas. So that it can be concluded there is a moderate relationship between planning and the realization of health operational assistance at the Puskesmas
\end{abstract}

Keywords: BOK, Health Operational Budget, PUSKESMAS 


\section{PENDAHULUAN}

Puskesmas sebagai fasilitas pelayanan kesehatan tingkat pertama yang menyelenggarakan pelayanan kesehatan perorangan dan pelayanan kesehatan masyarakat, bertanggungjawab pada wilayah kerjanya.Dalam era Jaminan Kesehatan Nasional (JKN), fungsi Puskesmas seolah bergeser menjadi Upaya Kesehatan Perorangan (UKP).Dalam upaya mendorong dan lebih mengaktifkan kembali fungsi UKM Puskesmas, terutama dalam kegiatan luar gedung, serta agar dapat menjangkau pelayanan secara merata dan berkesinambungan, dibutuhkan dukungan biaya operasional, dan dukungan pembiayaan lainnya.Dana Bantuan Operasional Kesehatan merupakan salah satu sumber pendanaan untuk menunjang operasional pelayanan di Puskesmas (Permenkes RI, 2019).

Saat ini BOK cenderung menjadi anggaran utama untuk operasional program kesehatan di Puskesmas.Porsi Anggaran Pendapatan dan Belanja Daerah (APBD) untuk operasional program kesehatan di Puskesmas semakin menurun, sehingga kinerja Puskesmas cenderung statis. Seiring dengan terbitnya UndangUndang Nomor 6 Tahun 2014 tentang Desa dan Undang-Undang Nomor 24 Tahun 2011 tentang BPJS (Badan Penyelenggaraan Jaminan Sosial) dan peraturan turunannya yang mengatur dana kapitasi untuk Puskesmas, diharapkan terjadi sinergisme pembiayaan operasional Puskesmas, sehingga akan semakin meningkatkan capaian pembangunan kesehatan (Kemenkes RI, 2015b).

Setiap daerah akan mendapatkan anggaran dalam pengelolaan dana kesehatan, kebijakan BOK ini masih terus berlangsung sampai saat ini dengan adanya pengalihan anggaran di Pusat yang semula bersumber dari dana Tugas Pembantuan (Tahun 2010-2015) menjadi Dana Alokasi Khusus Non Fisik Bidang Kesehatan. Pengalihan ini dimaksudkan untuk mempercepat pengalihan anggaran belanja Kementerian/Lembaga khususnya dekonsentrasi dan tugas pembantuan yang sudah menjadi urusan daerah ke Dana Alokasi Khusus serta mengakomodasi usulan kebutuhan dan prioritas daerah dalam mendukung pencapaian prioritas nasional (Proposal Based) (Kemenkes, 2016).

Tata kelola program dan manajemen harus terus menerus ditingkatkan ke arah yang lebih baik, melalui sinergitas pusat dan daerah, satu kesatuan siklus manajemen yakni perencanaan, penganggaran, pelaksanaan, pemantauan dan evaluasi sampai pada pertanggung jawaban serta pengadministrasiannya (Kementerian Kesehatan, 2015).Pemanfaatan Dana BOK difokuskan pada upaya promotif dan preventif yang meliputi Kesehatan Ibu dan Anak, KB, Imunisasi, Perbaikan Gizi Masyarakat, Promosi Kesehatan, Kesehatan Lingkungan dan Pemberantasan Penyakit. Alokasi dana BOK tahun 2017 tersebar di 280 Puskesmas Provinsi Sulawesi Tenggara dengan pagu anggaran sebesar Rp. 44.839.354.000, dan realisasi anggaran sebesar Rp. 44.635.732.366 (99,5\%). Data dari Dinas Kesehatan Provinsi Sulawesi Tenggara menjelaskan tentang realisasi anggaran TP BOK menurut Kabupaten Kota bahwa pada tahun 2017 terdapat 5 Kabupaten/Kota dengan realisasi BOK 100\% yakni Buton, Konawe, Kolaka Utara, Konawe Utara, dan Kolaka Timur. Sedangkan Kota Kendari dan Kabupaten/Kota lainnya belum mencapai 100\% (Dinkes Provinsi Sultra, 2018).

Alasan penelitian ini dilakukan adalah untuk mengetahui secara menyeluruh faktor-faktor yang diperlukan dalam realisasi anggaran BOK agar tepat sasaran dan tepat guna.Tujuan khusus yang ingin dicapai adalah Menganalisis hubungan perencanaan dan pelaksanaan realisasi anggaran BOK di Puskesmas. Maka cara 
yang akan dilakukan adalah mengumpulkan semua faktor-faktor yang ada di PUSKESMAS setempat untuk diolah datanya agar memperoleh haisl yang akurat.

Sehingga menghasilkan dokumen yang akan dijadikan acuan dalam mengelola dan melaksanakan anggaran BOK.

\section{METODE PENELITIAN}

Jenis penelitian yang digunakan adalah penelitian kuantitatif dengan rancangan Cross Sectional Study yaitu penelitian yang dilakukan pada waktu dan tempat secara bersamaan (Notoatmodjo, 2010). Penelitian ini hendak menganalisis hubungan antara variabel independen dengan variabel dependensesuai dengan metodepenelitian kuantitatif dengan rancangan Cross Sectional StudyPopulasi dalam penelitian ini adalah seluruh petugas pengelola BOK dan Koordinator Program di Puskesmas dan Dinas Kesehatan Kota Kendari yang berjumlah 157 orang (Dinkes Kota Kendari, 2019).Jumlah sampel dalam penelitian sebanyak 112 orang.Dalam memperoleh data yang akurat, peneliti mengadakan observasi langsung pada setiap responden, guna untuk mendapatkan data yang valid dan Analisis data yang digunakan adalah deskriptif dilakukan untuk mengidentifikasi variabel-variabel penelitian maka dilakukan secara deskriptifTeknik penarikan sampel dalam penelitian ini menggunakan simple random sampling yakni suatu teknik penarikan sampel dengan menggunakan acak sederhana atau lot. Variabel independen atau variabel bebas dalam penelitian ini adalah "perencanaan, pelaksanaan, pengawasan, pencatatan dan pelaporan" dan Variabel dependen atau variabel terikat dalam penelitian ini adalah "realisasi anggaran BOK dan cakupan program kesehatan".

\section{HASIL DAN PEMBAHASAN}

Puskesmas di wilayah kota Kendari terdiri dari 15 Puskesmas, yang terdiri dari 5 Puskesmas Perawatan dan 10 Puskesmas non perawatan. Rasio Puskesmas terhadap penduduk Kota Kendari mencapai 5 Puskesmas per 100.000 penduduk.Artinya 1 Puskesmas melayani rata-rata 20.000. Puskesmas tersebut yaitu Puskesmas Mata, Puskesmas Poasia, Puskesmas Benu-Benua, Puskesmas Kemaraya, Puskesmas Labibia, Puskesmas Jati Raya, Puskesmas Perumnas, Puskesmas Mekar, Puskesmas Lepo-Lepo, Puskesmas Wua-Wua, Puskesmas Puuwatu, Puskesmas Abeli, Puskesmas Mokoau, Puskesmas Nambo dan Puskesmas Kandai (Profil Dinas Kesehatan Kota Kendari, 2017). Sarana kesehatan lainnya yaitu Puskesmas Pembantu (Pustu) Kota Kendari sebanyak 21 buah Pustu.Tersebar pada 9 Puskesmas.Puskesmas yang belum memiliki Pustu adalah Puskesmas Kemaraya dan Puskesmas Benu-Benua. 


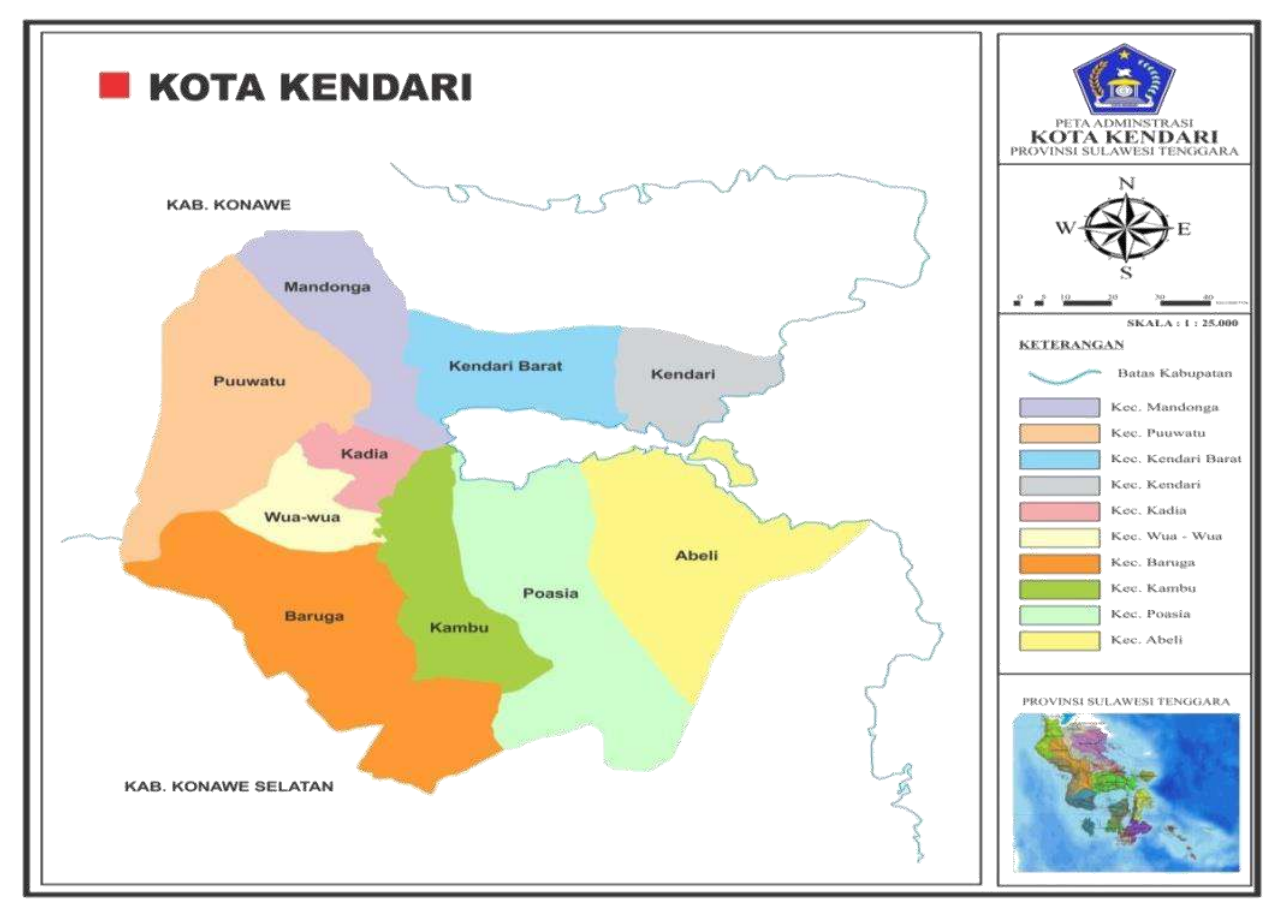

Gambar 3. Peta Administratif Kota Kendari

Tabel 1. Distribusi Responden Menurut Kelompok Umur Di Puskesmas

\begin{tabular}{cccc}
\hline No. & Kelompok Umur (Tahun) & $\mathbf{n}$ & $\boldsymbol{\%}$ \\
\hline 1. & $24-29$ & 28 & 25,0 \\
2. & $30-35$ & 32 & 28,6 \\
3. & $36-41$ & 18 & 16,1 \\
4. & $42-47$ & 23 & 20,5 \\
5. & $48-53$ & 11 & 9,8 \\
\hline \multicolumn{4}{r}{} \\
\hline
\end{tabular}

Tabel 2. Deskripsi Variabel Perencanaan

\begin{tabular}{|c|c|c|c|c|c|c|c|c|c|c|c|c|}
\hline \multirow{3}{*}{ No } & \multirow{3}{*}{$\begin{array}{l}\text { Item } \\
\text { (Butir) }\end{array}$} & \multicolumn{11}{|c|}{ Kriteria } \\
\hline & & \multicolumn{2}{|c|}{ SS } & \multicolumn{2}{|c|}{$\mathbf{S}$} & \multicolumn{2}{|c|}{ RR } & \multicolumn{2}{|c|}{ TS } & \multicolumn{2}{|c|}{ STS } & \multirow{2}{*}{ Mean } \\
\hline & & $\mathbf{n}$ & $\%$ & $\mathrm{n}$ & $\%$ & $\mathrm{n}$ & $\%$ & $\mathrm{n}$ & $\%$ & $\mathbf{n}$ & $\%$ & \\
\hline 1 & $\mathrm{X} 1$ & 11 & 9,8 & 97 & 86,6 & 4 & 3,6 & 0 & 0 & 0 & 0 & 4,06 \\
\hline 2 & $\mathrm{X} 2$ & 17 & 15,2 & 59 & 52,7 & 36 & 32,1 & 0 & 0 & 0 & 0 & 3,83 \\
\hline 3 & $\mathrm{X} 3$ & 11 & 9,8 & 48 & 42,9 & 45 & 40,2 & 8 & 7,1 & 0 & 0 & 3,55 \\
\hline 4 & $\mathrm{X} 4$ & 8 & 7,1 & 47 & 42,0 & 37 & 33,0 & 20 & 17.9 & 0 & 0 & 3,38 \\
\hline 5 & $\mathrm{X} 5$ & 2 & 1,8 & 58 & 51,8 & 37 & 33,0 & 15 & 13,4 & 0 & 0 & 3,42 \\
\hline 6 & X6 & 3 & 2,7 & 60 & 53,6 & 31 & 27,7 & 18 & 16,1 & 0 & 0 & 3,43 \\
\hline 7 & X7 & 9 & 8,0 & 36 & 32,1 & 47 & 42,0 & 20 & 17,9 & 0 & 0 & 3,30 \\
\hline 8 & X8 & 7 & 6,2 & 47 & 42,0 & 34 & 30,4 & 24 & 21,4 & 0 & 0 & 3,33 \\
\hline 9 & X9 & 5 & 4,5 & 50 & 44,6 & 31 & 27,7 & 26 & 23,2 & 0 & 0 & 3,30 \\
\hline 10 & X10 & 1 & 0,9 & 43 & 38,4 & 42 & 37,5 & 26 & 22,3 & 0 & 0 & 3,16 \\
\hline \multicolumn{2}{|c|}{ Jumlah } & 74 & 6,6 & 54 & 48,7 & 344 & 30,7 & 157 & 14,0 & 0 & 0 & \\
\hline
\end{tabular}

Tabel 2 diatas menunjukkan jumlah jawaban responden yang menjawab berdasarkan kuesioner perencanaan untuk kriteria sangat setuju (SS) sebanyak 
6,6\%, untuk kriteria setuju (S) sebanyak 48,7\%, untuk kriteria ragu-ragu (RR) sebanyak $30,7 \%$, dan untuk kriteria tidak setuju sebanyak $14,0 \%$

Tabel 3. Distribusi Responden Berdasarkan Perencanaan dengan Realisasi Anggaran Bantuan Operasional Kesehatan dan Cakupan Program di Puskesmas

\begin{tabular}{cccc}
\hline No. & Perencanaan & n & \% \\
\hline 1. & Baik & 74 & 66,1 \\
2. & Kurang & 38 & 39,9 \\
\hline & Total & 122 & 100 \\
\hline
\end{tabular}

Tabel 3 diatas menunjukkan bahwa dari 122 responden dengan perencanaan kategori baik berjumlah 74 orang $(77,0 \%)$ sedangkan perencanaan kategori kurang berjumlah 38 orang $(23,0 \%)$.

Tabel 4.Deskripsi Variabel Pelaksanaan

\begin{tabular}{ccccccccccccc}
\hline & & \multicolumn{10}{c}{ Kriteria } \\
\cline { 3 - 13 } No & Item & \multicolumn{1}{c}{ SS } & \multicolumn{1}{c}{ S } & \multicolumn{1}{c}{ RR } & \multicolumn{3}{c}{ TS } & STS & Mean \\
\cline { 3 - 13 } & (Butir) & n & \% & n & \% & n & \% & n & \% & n & \% & \\
\hline 1 & X1 & 15 & 13,4 & 96 & 85,7 & 1 & 0,9 & 0 & 0 & 0 & 0 & 4,12 \\
2 & X2 & 21 & 18,8 & 67 & 59,8 & 21 & 18,8 & 3 & 2,7 & 0 & 0 & 3,95 \\
3 & X3 & 7 & 6,2 & 45 & 40,2 & 46 & 41,1 & 14 & 12,5 & 0 & 0 & 3,40 \\
4 & X4 & 12 & 10,7 & 36 & 32,1 & 35 & 31,2 & 29 & 25,9 & 0 & 0 & 3,28 \\
5 & X5 & 6 & 5,4 & 40 & 35,7 & 43 & 38,4 & 23 & 20,5 & 0 & 0 & 3,26 \\
6 & X6 & 2 & 1,8 & 49 & 43,8 & 34 & 30,4 & 27 & 24,1 & 0 & 0 & 3,23 \\
7 & X7 & 9 & 8,0 & 39 & 34,8 & 35 & 31,2 & 29 & 25,9 & 0 & 0 & 3,25 \\
8 & X8 & 7 & 6,2 & 32 & 28,6 & 42 & 37,5 & 31 & 27,7 & 0 & 0 & 3,13 \\
9 & X9 & 3 & 2,7 & 37 & 33,0 & 32 & 28,6 & 40 & 35,7 & 0 & 0 & 3,03 \\
10 & X10 & 4 & 3,6 & 45 & 40,2 & 28 & 25,0 & 35 & 31,2 & 0 & 0 & 3,16 \\
\hline \multicolumn{2}{c}{ Jumlah } & 86 & 7,7 & 486 & 43,4 & 317 & 28,3 & 231 & 20,6 & 0 & 0 & \\
\hline
\end{tabular}

Tabel 4. diatas menunjukkan jumlah jawaban responden yang menjawab berdasarkan kuesioner pelaksanaan untuk kriteria sangat setuju (SS) sebanyak $7,7 \%$, untuk kriteria setuju (S) sebanyak $43,4 \%$, untuk kriteria ragu-ragu (RR) sebanyak $28,3 \%$, dan untuk kriteria tidak setuju sebanyak $20,6 \%$.

Tabel 5. Distribusi Responden Berdasarkan Pelaksanaan dengan Realisasi Anggaran Bantuan Operasional Kesehatan dan Cakupan Program di Puskesmas

\begin{tabular}{cccc}
\hline No. & Pelaksanaan & n & \% \\
\hline 1. & Baik & 65 & 58,0 \\
2. & Kurang & 47 & 42,0 \\
\hline & Total & 112 & 100 \\
\hline
\end{tabular}

Tabel 5 diatas menunjukkan bahwa dari 112 responden dengan pelaksanaan kategori baik berjumlah 65 orang $(58,0 \%)$ sedangkan pelaksanaan kategori kurang berjumlah 47 orang $(42,0 \%)$. 
Tabel 6. Analisis Inferensial hubungan Perencanaan dengan Realisasi BOK di Puskesmas

\begin{tabular}{lccccccc}
\hline & \multicolumn{4}{c}{ Realisasi BOK } & \multicolumn{2}{c}{ Jumlah } \\
\cline { 3 - 7 } No & \multirow{2}{*}{ Perencanaan } & \multicolumn{2}{c}{ Baik } & \multicolumn{2}{c}{ Kurang } & & \\
\cline { 3 - 7 } & & $\mathrm{n}$ & $\%$ & $\mathrm{n}$ & $\%$ & $\mathrm{n}$ & $\%$ \\
\hline 1. & Baik & 57 & 77,0 & 17 & 23,0 & 74 & 100 \\
2. & Kurang & 9 & 23,7 & 29 & 76,3 & 38 & 100 \\
\hline & Total & 66 & 58,9 & 46 & 41,1 & 112 & 100 \\
\hline
\end{tabular}

Tabel 6 diatas menunjukkan hasil analisis hubungan antara perencanaan dengan realisasi BOK, diperoleh bahwa dari 74 responden yang memiliki perencanaan baik, lebih banyak yang memiliki realisasi BOK baik sebanyak 57 orang $(77,0 \%)$ dan memiliki realisasi BOK kurang sebanyak 17 orang $(23,0 \%)$. Kemudian dari 38 responden yang memiliki perencanaan kurang, lebih banyak yang memiliki realisasi BOK kurang yakni 29 orang $(76,3 \%)$ dan memiliki realisasi BOK baik sebanyak 9 orang $(23,7 \%)$.

Hasil uji statistik menunjukkan bahwa nilai (X2hit) $=27,335>\mathrm{X} 2 \mathrm{tab}=$ 3,841, artinya bahwa ada hubungan antara perencanaan dengan realisasi bantuan operasional kesehatan di Puskesmas Kota Kendari. Selanjutnya, hasil uji keeratan hubungan diperoleh bahwa nilai yaitu 0,513 atau menunjukkan hubungan sedang.

Tabel 7. Analisis Inferensial hubungan Pelaksanaan dengan Realisasi BOK di Puskesmas

\begin{tabular}{cccccccc}
\hline & & \multicolumn{4}{c}{ Realisasi BOK } & \multicolumn{2}{c}{ Jumlah } \\
\cline { 3 - 6 } No & \multirow{2}{*}{ Pelaksanaan } & \multicolumn{2}{c}{ Baik } & \multicolumn{2}{c}{ Kurang } & & \\
\cline { 3 - 7 } & & $\mathrm{n}$ & $\%$ & $\mathrm{n}$ & $\%$ & $\mathrm{n}$ & $\%$ \\
\hline 1. & Baik & 52 & 80,0 & 13 & 20,0 & 65 & 100 \\
2. & Kurang & 14 & 29,8 & 33 & 70,2 & 47 & 100 \\
\hline & Total & 66 & 58,9 & 46 & 41,1 & 112 & 100 \\
\hline
\end{tabular}

Tabel 7 diatas menunjukkan hasil analisis hubungan antara pelaksanaan dengan realisasi BOK, diperoleh bahwa dari 65 responden yang memiliki pengawasan baik, lebih banyak terdapat pada yang memiliki realisasi BOK baik sebanyak 52 orang $(80,0,0 \%)$ dan memiliki realisasi BOK kurang sebanyak 13 orang $(20,0 \%)$. Kemudian dari 57 responden yang memiliki pengawasan kurang, lebih banyak yang memiliki realisasi BOK kurang yakni 33 orang $(70,2 \%)$ dan memiliki realisasi BOK baik sebanyak 9 orang $(29,8 \%)$.

Hasil uji statistik menunjukkan bahwa nilai (X2hit) $=26,379>$ X2tab $=$ 3,841 , artinya bahwa ada hubungan antara pelaksanaan dengan realisasi bantuan operasional kesehatan di Puskesmas Kota Kendari. Selanjutnya, hasil uji keeratan hubungan diperoleh bahwa nilai yaitu 0,504 atau menunjukkan hubungan sedang.

\section{Hubungan Perencanaan dengan Realisasi BOK}

Perencanaan kesehatan yang baik menurut Leavy \& Loomba harus mampu mewakili sebuah masalah dan kebutuhan masyarakat, menentukan tujuan dan 
sasaran secara spesifik, memperkirakan kemampuan yang dimiliki dan mampu menentukan model evaluasi yang tepat (Azwar, 2006).

Hasil penelitian menunjukkan bahwa hipotesis diterima.artinya bahwa ada hubungan antara perencanaan dengan realisasi bantuan operasional kesehatan di Puskesmas Kota Kendari.Selanjutnya, hasil uji keeratan hubungan diperoleh bahwa nilai yaitu 0,513 atau menunjukkan hubungan sedang. Pada tahap perencanaan misalnya ditemukan adanya keterlambatan proses perencanaan di tingkat puskesmas karena terlambat diterimanya Juknis BOK oleh puskesmas. SDM puskesmas juga masih lemah dalam membuat fokus dan arah kegiatan yang efektif bagi peningkatan derajat kesehatan masyarakat.Kualitas perencanaan masih rendah. SDM puskesmas belum memiliki kemampuan untuk menganalisis akar masalah kesehatan sehingga jenis kegiatan yang dibuat sebagian besar berbasis pada contoh kegiatan ada dalam Juknis dan jenis kegiatannya relatif sama dari tahun ke tahun. Di sisi lain, pendampingan dan pembinaan dari dinas kesehatan juga sangat kurang. Selama ini puskesmas tidak memiliki target program yang terarah dan terukur. Implikasinya, kegiatan yang dilakukan oleh puskesmas tidak diarahkan pada pencapaian kinerja pelayanan secara makro tetapi hanya sekedar memenuhi persyaratan dan tuntutan kebijakan pemerintah pusat semata.

\section{Hubungan Pelaksanaan dengan Realisasi BOK}

Pelaksanaan merupakan aktifitas atau usaha-usaha yang dilaksanakan untuk melaksanakan semua rencana dan kebijaksanaan yang telah dirumuskan dan ditetapkan dengan dilengkapi segala kebutuhan, alat-alat yang diperlukan, siapa yang melaksanakan, dimana tempat pelaksanaannya mulai dan bagaimana cara yang harus dilaksanakan, suatu proses rangkaian kegiatan tindak lanjut setelah program atau kebijaksanaan ditetapkan yang terdiri atas pengambilan keputusan, langkah yang strategis maupun operasional atau kebijaksanaan menjadi kenyataan guna mencapai sasaran dari program yang ditetapkan semula (Nurdin, 2012).

Hasil penelitian menunjukkan bahwa hipotesis diterima.artinya bahwa ada hubungan antara pelaksanaan dengan realisasi bantuan operasional kesehatan di Puskesmas Kota Kendari.Selanjutnya, hasil uji keeratan hubungan diperoleh bahwa nilai yaitu 0,504 atau menunjukkan hubungan sedang. Sejauh ini, dana BOK di Kota Kendari telah dirasakan atau berdampak kepada masyarakat sasaran. Hasil observasi langsung pada beberapa kegiatan di Posyandu diketahui bahwa berbagai kegiatan penyuluhan telah dilaksanakan dan informasi dari pengelola program, bidan, maupun kader menyebutkan bahwa dana operasional disediakan dari puskesmas. Tetapi, aspek ketepatan prioritas dari penggunaan dana kegiatan belum diketahui secara jelas. Hal ini juga merupakan aspek yang penting dan semakin harus berbasis bukti.Bukti yang dibutuhkan adalah terutama biaya nyata kegiatan kesehatan, biaya untuk penyakit yang dapat dihindari, efek langsung pada status kesehatan, dan keuntungan ekonomi tidak langsung dari kesehatan.

\section{SIMPULAN DAN SARAN Simpulan}

Berdasarkan penelitian yang telah dilakukan di Puskesmas, maka yang menjadi kesimpulan dari penelitian ini adalah sebagai berikut:Ada hubungan sedang antara perencanaan dengan realisasi bantuan operasional kesehatan di 
Puskesmas, dan ada hubungan sedang hubungan antara pelaksanaan dengan realisasi bantuan operasional kesehatan di Puskesmas.

\section{Saran}

Berdasarkan penelitian yang telah dilakukan di Puskesmas, maka yang menjadi saran dari penelitian ini adalah sebagai berikut

1. Membentuk tim pengawas internal tingkat dinas kesehatan kabupaten untuk meminimalisir kekurangan tersebut. Membina Puskesmas dalam penyusunan POA. Realokasi dan redistribusi tenaga kesehatan untuk menjamin teraksesnya pelayanan kesehatan oleh masyarakat.

2. SDM yang terlibat dalam program BOK diberi bekal materi yang cukup, sistem pelaporan dan pertanggung jawaban perlu dilakukan penyempurnaan tanpa harus mengurangi akurasi dukungan dokumen, hal tersebut diharapkan bisa mengurangi kesulitan dan keterlambatan pelaporan.

3. Dinas Kesehatan setiap tahunnya perlu untuk mengadakan pelatihan manajemen dan P2KT (Perencanaan dan Penganggaran Kesehatan Terpadu) kepada SDM yang terkait langsung dengan pengelolaan maupun terlibat dalam program yang dibiayai BOK.

4. Puskesmas sangat perlu memanfaatkan forum lokakarya mini dengan baik untuk menyusun POA yang tepat sasaran dengan mengacu pada kebijakan yang ada. Selanjutnya diharapkan POA yang disusun dengan baik agar memperlancar pencairan BOK.

5. Perlu peningkatan serta alokasi dana yang tepat waktu dari dinas kesehatan kota Kendari supaya tidak perlu ada peminjaman dana ataupun kegiatan yang dibiayai sendiri oleh petugas sehingga pelayanan kesehatan tidak tarhambat.

\section{UCAPAN TERIMAKASIH (Bila Ada)}

Seluruh Kepala Puskesmas yang ada di Kota Kendari Sulawesi Tenggara.

\section{DAFTAR PUSTAKA}

ASMARIPAAINY 2012. Pelaksanaan Kebijakan Bantuan Operasional Kesehatan Di Kabupaten OganIlir. Jurnal Kebijakan Kesehatan Indonesia, 1.

AZWAR, A. 2010. Pengantar Administrasi Kesehatan, Jakarta, Binarupa Aksara.

BASRI, R. 2013. Analisis Penyusunan Anggaran dan Laporan Realisasi Anggaran Pada BPM-PD Provinsi Sulawesi Utara. Jurnal EMBA: Jurnal Riset Ekonomi, Manajemen, Bisnis dan Akuntansi, 1.

DEDI, A. 2012. Manajemen Pelayanan Kesehatan, Yogyakarta, Nuha Medika.

DINKES KOTA KENDARI 2018. Profil Kesehatan Kota Kendari, Kendari, Dinas Kesehatan Kota Kendari.

DINKES PROVINSI SULTRA 2018. Laporan Profil Kesehatan Provinsi Sulawesi Tenggara, Kendari, Dinas Kesehatan

EVELYN, M. 2011. Evaluasi Implementasi Kebijakan Bantuan Operasional Kesehatan di Tiga Puskesmas Kabupaten Ende Provinsi Nusa Tenggara Timur. Kebijakan Kesehatan Indonesia, 01, 161-167.

FADILAH, S. 2009. Activity Based Costing (ABC) Sebagai Pendekatan Baru Untuk Menghitung Analisis Standar Belanja (ASB) Dalam Penyusunan 
Anggaran Pendapatan Belanja Daerah (APBD). Jurnal Telaah \& Riset Akuntansi, 2, 54-78.

HUSNI, F. 2012. Efektifitas Bantuan Operasional Kesehatan Di Kabupaten Bintan Provinsi Kepulauan Riau Tahun 2011 dan Tahun 2012. Universitas Indonesia.

IMAM, M. 2011. Implementasi Kebijakan Bantuan Operasional Kesehatan (BOK) Di Kabupaten Bandung Barat. Jurnal Skripsi, 1.

KEMENKES 2013. Bahan Paparan Jaminan Kesehatan Nasional dalam Sistem Jaminan Sosial Nasional. In: KESEHATAN, D. (ed.). Jakarta.

KEMENKES, R. 2016. Profil Kesehatan Indonesia 2015. Jakarta: Departemen Kesehatan.

KEMENKES RI 2011. Petunjuk Teknis Bantuan Operasional Kesehatan. Jakarta.

KEMENKES RI 2015a. Petunjuk Teknik Pelaksanaan Dana Bantuan Operasional Kesehatan, Jakarta, Kementrian Kesehatan.

KEMENKES RI 2015b. Profil Kesehatan Indonesia. Jakarta.

MUNINJAYA, P. D. A. A. G. 2015. Manajemen Kesehatan Ed.3, Jakarta, Penerbit Buku Kedeokteran EGC.

NOTOATMODJO, S. 2010. Metodologi Penelitian Kesehatan, Jakarta, Rineka Cipta.

PERMENKES RI 2014. Peraturan Mentri Kesehatan Nomor 75 Tahun 2014 Tentang Pusat Kesehatan Masyarakat, Jakarta, Kementrian Kesehatan.

PERMENKES RI 2019. Petunjuk Teknis Penggunaan Dana Alokasi khusus Nonfisik Bidang Kesehatan Tahun Anggaran 2019, Jakarta, Kementrian Kesehatan.

PUTRI, U. 2012. Hubungan Antara Realisasi Dana Bantuan Operasional Kesehatan Dengan Indikator Gizi Kia Di Kabupaten/Kota Provinsi Jawa Tengah Tahun 2012. Jurnal Kebijakan Kesehatan Indonesia, Volume 2, 215-221.

RIZKY, S. R. 2012. Pengaruh Evaluasi Anggaran Terhadap Kinerja Satuan Kerja Perangkat Daerah (SKPD) Pemerintah provinsi Sumatera Utara. Jurnal Ekonom, 1, 42-52.

SAEFULLAH 2005. Pengembangan Sumber Daya Manusia, Jakarta, Grasindo.

SUGIYONO, P. D. 2011. Metode Penelitian Kuantitatif Kualitatif dan $R \& D$, Bandung, Alfabeta

TRIHONO 2005. Manajemen Puskesmas Berbasis Paradigma Sehat, Jakarta, Sagung Seto.

USMAN, N. 2012. Konteks Implementasi Berbasis Kurikulum, Jakarta, PT. Raja Grafindo Persada. 